\title{
Review of Printopolis, edited by Tara Cooper and Jenn Law (2016)
}

\author{
Haley Toll, Memorial University
}

hrmtoll@,mun.ca

Keywords: Printmaking; Print Media; Art Symposium; Open Studio; General Idea; Print

Culture; Canadian Art

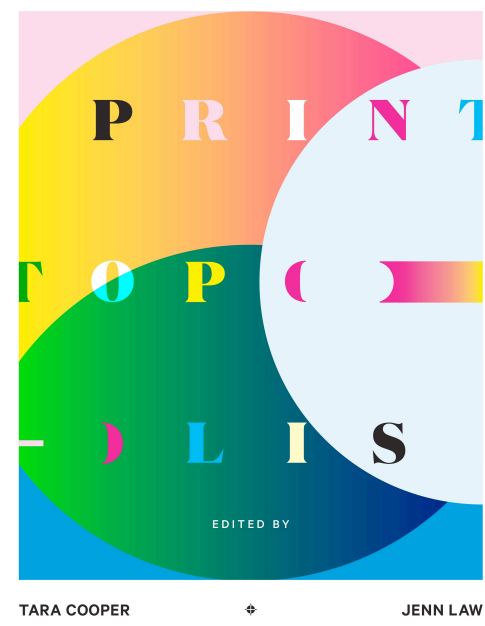

Figure 1. Printopolis cover page.

$\mathrm{P}$ rintopolis is based on the living event of the 2010 international symposium of artists, curators, writers, and arts enthusiasts. This was hosted by Toronto's Open Studio, Canada's prominent artist-run printmaking centre to celebrate the studio's $40^{\text {th }}$ anniversary. With this publication, Cooper and Law (2016) intended to capture the discourse of the symposium. The collection asserts printmaking's prominence as an artistic practice and looks back at Open Studio's legacy in the changing artistic landscape of digital technologies. The work describes the media's multifaceted nature in our everyday lives, community focus, and print media's adaptability to counter notions that printmaking is a dead practice (Balfour, 2016). Diverse topics, such as street art, community practice, archiving, collecting, interdisciplinary materiality, artist's ephemera and printmaking theoretical underpinnings are explored.

The breadth of topics covered in this book is inspiring for the reader. The collection of chapters, interviews and artwork is a fully separate experience from the symposium that took place seven years ago. The volume transports the reader to a space that contains multiple (and yet parallel) perspectives and critical discourse on historical and contemporary Canadian print culture. Through its textuality, Printopolis creates a permanent space, which defines and critiques how printmaking lives in Canadian society. The book chronicles 25 articles and artworks that explore how printmaking is created, situated and experienced. It is written by artists, curators, collectors and art historians, including Richard Sewell, Barbara Balfour, Yael Brotman, Dave Dyment, Shannon Gerard, Liz Parkinson, Lisa Deanne Smith, Mary Tremonte, 
et. al. Heidi Hill's videoconference interview transcript with General Idea's A.A. Bronson was notable and compelling. Hill and Bronson's text takes on a contemplative, humorous, easygoing, and yet simultaneously weighty dialog on the development and challenges of Canadian artist experiences.

This volume reflects the collective and communal values of Open Studio practice. The constellation of individual articles each stand on their own as unique pieces, and concurrently contribute to the larger whole. The work holds a collection of voices and art expressions that embody and bestow the wisdom of successional knowledge. Some voices feel more intimate and artistically evocative, such as pieces by Parkinson, Balfour, Cooper and Brotman. Meanwhile, Lewin, Welch, Dyment and Law's writings contain larger macro perspectives with a scholarly art historical lens. I recommend the articles be read as separate pieces, leaving time in-between the texts to contemplate and digest the writings. Otherwise, the articles may feel oversaturated and compete with one another due to their individual weightiness. I recommend this volume be read and examined in post-secondary Canadian printmaking studies, and used within academic curricula to inform scholarly discourse about printmaking. The volume is relevant beyond the academic realm and may interest collectors, practicing artists and printmaking enthusiasts. The bright and evocative images add symbolic depth to the experience of Printopolis (Figure 1).

The text structure is divided into four chapters based on general themes, each of which contain 5-8 articles and artworks. The print artworks were specifically designed for the book's aesthetic. The sections include the topics of collecting, distribution, contemporary experiences and the legacy of Open Studio. The first article in Chapter 1 opens with Parkinson (2016) detailing her passionate and wonder-filled artistic collecting process. She connects her experience to prominent historical collectors, evolutionary, and philosophical theories. The author poetically states, "It is a petition towards passion and wonder; an evocation of the generative power of objects in negotiation with other objects in the collection, and with the collector herself" (Parkinson, 2016, p. 31). Stemming from this reading, I expected the book to contain more introspective descriptions of artistic processes. This was not the case, as the articles discussed below cover contemporary, theoretical and historical concepts as opposed to an exploration of the creative process.

The two chapters, "Print distribution: Getting the word out" and "Print now: Thoughts on contemporary print" reflect on new ways of distributing prints and asserting printmaking's ubiquitous presence as a current valuable multifaceted medium. These chapters often touch upon themes of life, death and survivorship within contemporary times. Lewin's case study on the Kinngait Studios of Cape Dorset describes the studio maintaining longevity and sustainability through frequently integrating new ideas, while maintaining cultural and artistic authenticity.

Open Studio in Toronto more recently celebrated its $47^{\text {th }}$ anniversary. The articles within Chapter 4 narrate what feels like the high renaissance birth of artist-run-centres in the 1970s. The collective texts tie together nostalgic, contemplative and personal accounts of working in the Open Studio and are balanced with a yearning to fully support their substantial archive of 7,000 prints. This chapter fully embodies the collective and cooperative nature of the Open Studio, described by MacDonald, Menard \& O’Neill, Sewell et al., Livey, Brotman, \& Gerard.

Editors Cooper \& Law state (2016):

Our aim has been to engage critical discourse on print culture both locally and further afield. Although print remains one of the most pervasive, technologically revolutionary, and historically influential art forms, there exists a noted lack of critical writing on contemporary fine art printmaking and print theory more broadly (2016, p. 14). 
As a painter and academic who has only briefly delved into print media, I found the work illuminating. My lens allowed me to immerse myself within new ways of seeing. Printopolis is embedded with textual treasures that serve as sources of inspiration for artists working outside of printmaking. In my opinion, the work helps the reader navigate the world of print media in contemporary Canadian society. Similar to the creation of artists-run-centers in the 70s, this volume carves out spaces for printmaking to exist and thrive in contemporary and historical consciousness. This book is a printed artwork within itself. It is an archive that contains precious imaginal and textual media. 